\title{
"CARRERA" PROFESSIONAL I CICLE VITAL: CONTINUÏTAT I CANVI EN LA SOCIALITZACIÓ OCUPACIONAL DELS DOCENTS*
}

\author{
Lluís Samper \\ Universitat Autònoma de Barcelona
}

Resum

En aquest article, s'hi destaca la importància de la socialització ocupacional, més concretament del concepte de "carrera", com a element clat de la socialització adulta. Per aixó, es revisen algunes aportacions de la sociologia biogràfica al tema de la "carrera" docent. Aquesta revisió afronta la doble dimensió, teòrica $i$ metodologica, dels recents estudis sobre la interrelació entre trajectòria vital, personal, del mestre $i$ els seus contextos organitzatius i sòcio-històrics.

Restumen

En este articulo se destaca la importancia de la socialización ocupacional, más concretamente del concepto de "carrera", como elemento clave de la socialización adulta. A tal efecto, se revisan alounas aportaciones de la sociologia biográfica al tema de la ecarrera" docente. Dicha revisión enfrenta la doble dimensibn, tebrica y metodologica, de estudios recientes sobre la interrelación entre trayectoria vital, personal, del maestro y sus contextos organizativos y sociohistoricos.

Abstract

In this article we have emphasized the importance of occupational socialization, more precisely the concept of career, as a key element of adult socialization. In this way, we have revised some contributions of the biographical sociology on the subject of the teaching career. This aforesaid revision faces the double dimension, theoretical and methodological of recent studies on the interdependence of a teacher's life-span and his socio-historical and organizational contexts.

* Aquest trebalt escà relacionar amb una investigacib empirica sobre desenvolupamenr professional del mestre, referència DGICYT PS870086. 
"Papers»: Revista de Sociologia

\section{CAP A UN CONCEPTE DE SOCLALITZACIO OCUPACIONAL}

Deia Heràclit que no ens podem banyar dues vegades en el mateix riu, però si, acceptant el postulat hicraclitià que tot flueix i tor canvia, tornem al tema de les relacions entre els individus, hom pot, fins i tot, preguntar-se: ¿som els mateixos al llarg de la nostra trajectòria vital? Per exemple, ¿què tenim en comú amb nosaltres mateixos als $20,40 \circ 60$ anys? D'altra banda, ¿en quina mesura és comparable la nostra manera d'actuar en els diferents àmbits (laboral, familiar, lleure...) de la nostra vida quotidiana? ¿Com coincideix la nostra auroimatge com a fill, alumne, amic, col.lega, marit, veí... amb les nostres successives, i no sempre congruents, identitats socials? ¿Qui no coneix, per exemple, el cas del bippie dels 60 o del progre dels 70 metamorfosats en iuppie als 80?: Què fa canviar o romandre les nostres actituds, creences, afeccions al liarg dels anys? ¿Quins d'aquests canvis són superficials o efímers i què és allò que constituteix el nostre nucli cstable de personalitat?

Obviament, com assenyala Becker, (1968: 655), el "jo" canvia quan canvia la situació i roman estable quan la situació no canvia. És més, atès que la gent contínuament ha d'enfrontar-se amb noves situacions i successos inesperats, l'expressió "socializzació adulta" com a sinònim d'un aprencntatge social ocasional en àmbits cspecialitzats, és inadequada (Becker, 1968: 652). Contràriament al sentit comú, és l'estabilitat del jo allò que esdevé problemàtic.

Això no vol pas dir que, de la mateixa manera que les diferents societats es diferencien a causa de la presentació de grans variacions en els ritmes i en la intensitat dels processos de canvi social, anàlogament, tampoc no observem oscil.lacions profundes quant a la freqüència del canvi personal. Així, per exemple, en tna societat industrial avançada sembla possible de dir que, en un context generalitzar de canvi social, la residència, l'activitat laboral o el nivell d'escolarització condicionen el grau de modificació del "si matcix". A tall d'exemple, el pagès autònom que treballa tora la seva vida al mateíx poble, on va néixer, i del qual només el servei militar, el viatge de noces o la visita al metge especialista el separen temporalment d'una espessa xarxa de parents $i$ veïns, té evidentment ben poques probabilitats de redefinir el seu projecte de vida. Tanmateix, fins i tot en aquest cas, les seves successives posicions en l'estructura familiar i de parentiu i, molt cspecialment, els processos exògens de modernització (els avenços tecnològics, les fluctuacions del mercat agrícola i ramader, la penetració de l' "ethos" consumista a través dels mass media o bé la influència dels estiuejants...) faran que, d'una manera o attra, vagi variant els seus hàbits de consum, de vestir, de lleure $i$, a l'ensems, la seva pròpia manera de ser i de pensar. En aquest sentit, si admetem la interdependència entre canvi social i canvi personal, a la nostra societat resulta molt dificil, per 
no dir impossible, restar al marge del dinamisme i mutació de les condicions de vida ${ }^{\mathrm{t}}$.

Un segon principi, que cal tenir present per a una teoria de la socialitza. ció adulta, és diferenciar entre pseudocanvis adaptatius i els canvis a nivell del "Si mateix substancial" (Becker, 1968; Nias, 1985). De la mateixa manera que al cèlebre aforisme del príncep de Lampedusa, a l'àmbit del canvi personal, sovint cal que tot canviï perquè les coses continuïn igual. Dit altrament, no és infreqüient que els canvis a nivell de participació i d'identificació de l'individu en diferents grups socials tinguin un valor merament adaptatiu i serveixin, de fet, per preservar els aspectes més substancials del "jon. Per posar un exemple prou conegut per tothom, zcom explicar, si no és en termes d'estratègia destinada a garantir una identificació profunda amb el poder, una necesssitat de manar molt profundament arrelada en l'estruc. tura de la personalitat, les incongruents, aparentment, trajectòries biogràfico. ideològiques d'alguns politics? Es clar que no tot és fingiment o pscudocanvi. De vegades, com ja ho havia assenyalat Becker, el canvi afecta el nucli de la identitat personal, $i$ així veiem que s'ha bastit un nou "jo" estable, si més no durant un cert temps, concentrat-se intensament en un grup reduit de per-sones o d'activitats. Solament en aquest cas hom pot parlar, a parer nostre, de resocialització.

Malgrat que alguns rols, com el gènere i la concomitant identitat sexual, ocupen un lloc central, ancorat en les estructures profundes del "si mateix», en la identitat personal dels individus de qualsevol societat, hi ha importants variacions històrico-culturals respecte a la importància relativa de la resta dels aprenentatges socials. Així, en les societats pre-industrials, el parentiu, la religió o l'etnicitat juguen un paper important a l'hora de determinar l'autoimatge: el subjecte es percep (i ell mateix s'hi autoclassifica) com a membre de tal llinatge o grup de parentiu o en termes de pertinènça a una èrnia de.terminada. Contràriament, en la societat industrial avançada (sense subestimar, òbviament, el pes que encara tenen l'etnicitat o el gènere) la identitat personal dels individus adults, especialment si són homes ${ }^{2}$, rau, granment, en l'activitat ocupacional. En aquest sentit, el treball dels adults no sols condiciona objectivament les condicions de vida familiars (Giddens, 1980; Cohen, 1987: 15) sinó que, com ho ha escrit Kohn, (1985: 205) cl que fem o cl que deixem de fer en els nostres quefers laborals, afecta directament els nostres va.

1. Per raons d'espai, i d'oportunitat, no puc entrar aqui en el desgastament psíguic (i les: seves repercussions en l'estructura de personalitat) que implica el procés de resocialitzacions suc. cessives. Sobre aquest tema en remcto a Devercux, (1939) i Estcva, (1973).

2. Tot i que, més endavant, tornaté sobre aquest punt, les diferències entre ambdós sexes respecte al pes relatiu de la dimensió familiar vs. ocupacional en configuració de l'estabilitat i canvi de la identitat personal, mereixien, per la seva importància, un tractament monogrâfic. 
lors, els nostres autoconceptes i les nostres orientacions vers els altres ${ }^{3}$. Per exemple, quan volem esbrinar la identitat social d'un desconegut, la nostra primera font d'informació és el seu status laboral —o el de la seva família-, d'on avancem hipòtesis sobre el seu estil i condicions de vida, les seves preferències culturals $i$, fins $i$ tot, sobre la seva ideologia. A la nostra societat, "qui és quì equival a dir "què fa" o "a què es dedica".

Per complicar encara més les coses, el rol ocupacional no és aliè a les altres identitats personals (ser dona, per exemple, avui dia, encara limita l'accés a determinades activitats laborals; no parlem de ser gitano) i, encara més important, aquesta influència recíproca entre l'ocupació i les altres dimensions del nostre "si mateix" assoleix una dimensió biogràfico-temporal. Altrament, la seva naturalesa diacrònica, amb un input-output a l'activitat laboral, i també les seves variacions de "status", ens remeten al concepte de "carrera" o trajectòria professional (Mortimer, 1988). Seguint Johnson (1983), considerem convenient de diferenciar una triple dimensió en el concepte de "carrera": a) els padrons de "carrera", seqüència d'estadis determinats per les institucions socials (relativament al marge del propi esforç o voluntat de l'individu, comi l'edat oficial de jubilació); b) la "carrera» objectiva de l'individu, estadis resultants de l'activitat personal i/o que impliquen un canvi explícit d'ustatus" laboral (un mestre promogut a inspector d'ensenyament, per exemple), ic) la carrera subjectiva, que seria la interpretació dels fets del present i del passat associats a una identitat personal. Áquest concepte de "carrera" pressuposa, doncs, que la trajectòria (ascendent, descendent o discontínua, això no importa) laboral, l'edat cronològica, les circumstàncies biogràfico-personals (gènere i situació familiar, més concretament), el context organitzatiu $i$ institucional i la pròpia dinàmica social (crisi o expansió econòmica, per dir un exemple obvi) són variables que s'han d'analitzar conjuntament.

En el cas concret de la socialitzacio ocupacional dels mestres, l'enfocament predominant ha estat, llevat d'excepcions i d'estudis recents, funcionalista (Atkinson i Delamont, 1985). Per exemple, respecte al controvercit tema de l'autoritarisme dels docents, trets psicològics com la rigidesa de personalitat o la tendència al conformisme han estat interpretars en termes dels seus orígens socials o antecedents familiars, és a dir, com a resultant d'unes prèvies disposicions actitudinals, originàries de la socialització bàsica. Això no obstant, Lortie (1977),

3. Obviament, ni els aturats ni els nombrosos individus sotmesos a processos de treball fragmentats, monòtons i/o precaris no tenen massa oportunitats de configurar liur identitat a través del rol professional. Això no obstant, fins i tor en aqucst cas, per defecte, es demostra la importància de l'ocupació com a element configurador de la identirat personal en la societat industrial avançada. Sobre la progressiva deslegitimació de l'antiga ètica del creball i la centralitat dels rols octupacionals em remeto a Habermas (1973).

4. "Carreran traducció literal de career, com a trajectória laboral de qualsevol ripus i no en el sentit restringit, elitisra, que té la paraula carrera en la nostra llengua. 
ja havia subrallat la importància de la pròpia experiència docent en la confrgutració d'una sèrie de trets, com el predomini del conservadurisme sobre el radicalisme, de l'individualisme sobre el treball en equip i l'orientació cap al present enfront de la tendència a programar el futur. Conservadurisme, individualisme $\mathrm{i}$ "presentisme» foren, doncs, els components significatius de l'kethos" dels mestres d'escola (Lortie, 1977: 212). Però, segons aquest autor, aquests trets sòciopsicològics ens remeten a una anàlisis en profunditat de l'ofici de mestre. Així, el seu individualisme és una resposta lògica a l'estructura cel. Iular de la professió, al mateix temps que el seu mutu aîllament laboral agreuja el ja elevar gratu d'incertesa sobre l'eficàcia del seu treball. Això sol traduir-se, a més, en sentiments d'angoixa que poden reduir les activitats innovadores $\mathrm{i}$ justificar-ne les conservadores. Últimament, la carència d'una sòlida cultura tècnica que legitimi la seva pràctica professional els fa tendir a la subestimació $\mathrm{i}$ a la indefensió davant dels «intrusos" (pares, col.legues, directors o inspectors). D'aquesta manera, conservadurisme, individualisme $i$ (presentisme" tendeixen a reforçar-se mútuament fins al punt de configurar la subcultura ocupacional dels mestres. En altres paraules, al marge dels antecedents individuals dels ensenyants és la pròpia experiència laboral docent la que, ateses les estructures organitzatives de les escoles, acaba modelant, influint sobre la personalitat dels mestres.

D'altra banda, des d'una perspectiva interaccionista, Becker (1952), va introduir, en aquest àmbit de la investigació sociològica, el fructífer concepte de "carrera", que defineix com l'estructurada sèrie d'ajustaments realitzada per l'individu en la xarxa social d'institucions, organitzacions formals i relacions informals. Utilitzant una metodologia qualitativa, el seu estudi se centra en l'anàlisi de les trajectòries professionals de 60 mestres de les escoles públiques de Chicago. Un dels resultats més significatius fou justament constatar el predomini de la "carrera" horitzontal sobre la vertical; és a dir, el fet que la majoria de lęs seves entrevistades veien llur trajectòria laboral sols en termes de trasllat, sense modificació d' "status", entre diferents escoles i no com una promoció professional. Altrament dit, llur "carrera" es reduïa, bàsicament, a una recerca de millors condicions laborals que, a la vegada, estaven relacionades amb l'origen social dels alumnes. La mestra novella començava, usualment, la seva ucarrera" a l'escola de menor categoria (un centre on predominaven alumnes amb dificultats d'aprenentatge i problemes de disciplina) perquè, a la fi, pogués situar-se als llocs menys conflictius. També des d'aquesta perspectiva, Lacey (1977), va oferir una sèrie de resultats que qüestionaven seriosament el model funcionalista sobre l'adquisició de la cultura professional docent i l'ingrés a l'ensenyament, cosa, òbviament, molt més problemàtica i discontínua que a la clàssica teoria de la socialització.

No obstant això, si exceptuem aquest $i$ altres estudis semblants, fins a finals dels 60 el predomini de l'enfocament funcionalista, emfasitzant-ne la dimensió 
estructural-funcional, va reduir els mestres a unes figures secundàries dintre de la investigació sociològica sobre el sistema educatiu. Durant els 70 , el ressorgiment de l'interaccionisme i del marxisme comença a questionar el model black box de l'aula i s'estudia la manera concreta amb què l'escola "processa" els alumnes. Per a alguns investigadors, la desculpabilització de l'alumne es tradueix en el fet de responsabilitzar els mestres («etiquetatge" i utipificación són els conceptes clau) del fracàs escolar. Altres autors, al contrari, tendeixen a considerar els docents no com els botxins sinó com les víctimes de l'aparell escolar i desenvolupen teories sobre la desqualificació i proletarització dels treballadors de l'ensenyament sense faltar els que tendeixen a concentrar llur esforç en la denúncia del sexisme i de l'androcentrisme de l'activitat docent. Sols recentment, al llarg de l'última dècada, s'ha anat imposant una nova perspectiva, evolutiva i dialectica, que rracta d'anar integrant i superant les limitacions dels enfocaments anteriors (BaIl i Goodson, 1985). La hipòtesi central del nou enfocament és l'existència d'una interrelació entre els quaranta anys, aproximadament, que dura la trajectòria professional del mestre, les seves pròpies visicituds biogràfiques i el teló de fons macrosociològic en què desenvolupa la seva activitat. Això, al nostre parer, significa: 1) que els mestres, no solament els alumnes, són persones, i que, per tant, malgrat que són adults, també evolucionen respecte a llurs capacitats, aspiracions o necessitats; 2) que llur socialització ocupacional ha de ser estudiada com un procès continuat de reajustaments, és a dir, com una llarga trajectòria caracreritzada per variacions en els nivells de satisfacció, competència i implicació professional; 3) que aquestes transformacions (o estancaments) depenen més dels avatars concrets de la pròpia experiència docent $i$ de l'evolució de la seva identitat personal que, per exemple, dels motius d'elecció de carrera o la seva formació inicial, í 4) que aquesta "carrera», i també la pròpia biografia, són intelligibles solament en el marc de la dinàmica històrica en la qual es desenvolupa l'acció individual.

\section{ALGUNES QÜESTIONS PENDENTS}

En l'estat actual de la investigació, hi ha un ampli acord sobre l'existència d'estadis o etapes en la trajectòria professional dels mestres i també de la seva interdependència respecte al desenvolupament biogràfic. No obstant això, no hi ha consens pel que fa al nombre d'aquestes etapes (que oscil.len, segons els autors, entre tres i vuit), la denominació i llurs característiques i la seva periodització. Tampoc no hi ha informació suficientment contrastada que expliqui el pes relatiu dels diferents factors (personals, organitzatius, estructurals) en l'evolució, al llarg de la trajectòria ocupacional, de variables com la satisfacció, el compromís o la competència professional. 
La importància d'aquest tema, fins al punt que en alguns països europeus les administracions educatives promouen programes de suport als docents directament inspirades en el model del Life-Span Developament, rau en les seves implicacions a nivell de formació permanent i prevenció del Bur-nout dels mestres $^{5}$. Si les previsions actuals sobre un cert "envelliment» de la força de treball docent es confirmen (a gairebé tota Europa, per raons demogràfiques i econòmiques, la formació inicial dels mestres està reculant en favor de la inservice education) també aquí haurem de parar més atenció a aquestes qüestions.

Sabem que a la seva socialització ocupacional, els mestres, com qualsevol altre col.lectiu, utilitzen diferents estratègies adaptatives: interiorització de les normes "oficials", redefinició de la situació i corresponent conflicte amb la institució o, més freqüentment, una submissió aparent (Lacey, 1977: 111 i ss.). També sembla provat que aquestes i altres probables línies d'actuació tendeixen a anar-se consolidant a mesura que avança el cicle vital, donant lloc a un estil pedagògico-funcional idiosincràtic. $D^{\prime}$ altra banda, la literatura especialitzada (Fuller, 1969; Burke et alii, 1982; Nias, 1985-b; Sikes et alii, 1985...) coincideix a assenyalar que una majoria dels docents inicien la seva trajectòria professional superant una fase inicial de "supervivència", caracteritzada com una etapa d'iniciació, de recerca de seguretat i d'aprenentarge de tècniques de disciplines i maneig de continguts que permetin al mestre de superar una primera autoimatge com a "professional". Encara que, en la caracterització i periodització d'aquesta etapa inicial (sortir-se'n com sigui o deixar l'ofici, o com és usual de llegir a la bibliografia "nedar o ofegar-sen), hi coincideixen la major part dels autors, és a partir d'aquí, en l'elaboració d'un model teòric que expliqui i predigui els canvis i les continuïtats, les etapes i llurs característiques de la "carrera" docent, on comencen a sorgir les discrepàncies.

Tot i admetre la rellevància socializzadora d'aquesta primera fase d'entrada a l'ofici, és obvi que no tots els mestres, ni tan sols la majoria, resten ancorats en les rutines de supervivència. ¿Quins contextos organitzatius, per exemple, ajuden o dificulten la superació de l'estadi de usupervivència» i obren el camí cap a un creixement professional? Reighart (1984), ha destacat la importància dels primers anys de docència com a configuradors de la reputació del mestre $i$, en aquest sentit, com a responsables de la seva autoimatge. A mesura que se superin o no les tensions i desafiaments inicials, es pot avançar, amb bastant: de probabilitat, el risc d'estancament professional. Per aquest autor, i també

5. Com bé se sap, una alarmant proporció d'ensenyants acaben sofrint la "sindrome del malestar docent", dir altrament, ues cremen" professionalment. Encara que les seves manifestacions, percentatge (entre un...25 i un 35\%, segons les foncs) d'incidencia i les seves causes són afers controvertits, la cosa certa ès que, al marge dels topics, I'excercici professional de l'ensenyament pot genetar sentiments d'angoixa, frustació, depressió del "jo". per no parlar dels casos excepcionals de "malaltia mental" permanent. Quant a axxò, vegueu Baber i Miller, (1982); Fs. teve (1984); Freedman (1986); Prick i Horst (1986); Cole i Walker (1990). 
per a Ball i Goodson, (1985) són, en darrera instància, les condicions organitzatives ( $i$, entre elles, l'ingrés laboral) la variable de més pes a l'hora d'explicar la "carrera" ocupacional dels mestres i, en general, dels treballadors assalariats.

Sikes (Sikes et alii, 1985), tot scguint les teories de Levinson sobre els estadis del cicle vital, estableix una interrelació entre les etapes i crisis del període adult, la identitat personal i el desenvolupament professional. El seu estudi, basat en les històries de vida de 48 mestres de secundària, el porta a establir cinc fases biogràfico-ocupacionals; així, per exemple, relaciona la iniciació professional amb la crisi d'entrada en el món adult o les diferències de gènere a les carreres professionals en funció de la diferent significació que té per a les dones o per als homes la "crisi de la meitat de la vida" (Erikson, 1959; Gould, 1981; Levinson, 1981).

Al marge de la falta de consens sobre el nombre i característiques de les etapes en la "carrera" docent, també perquè hi ha dades insuficients i, fins i tot, contradictòries sobre les variables que condicionen els processos de canvi, hi ha un punt important en el qual tots coincideixen: el caràcter no lineal, no acumulatiu de la "carrera" docent. Davant del tòpic que a més experiència docent més desenvolupament professional i en oposició a l'enfocament tecnoeficientista dels administradors que avaluen el desenvolupament professional en termes de rendiment escolar, les investigacions empiriques sobre la "carreram docent refusen totalment la hipòtesi d'un itinerari biogràfico-professional unidimensional. Ni la "capacitat" docent (si de cas pogués avaluar-se al marge de criteris ideològics), ni la satisfacció, el compromís o l'autoconfiança dels mestres creixen o decreixen conjuntament $i$ lineal, segons seqüències acumulatives al llarg de la "carrera" ocupacional. Per exemple, el mestre "madur", definit per Fuller (1969) com aquell la preocupació del qual es localitza en el rendiment $i$ atutoestima de l'alumne en oposició a la preocupació per ell mateix, no és necessàriament el que porta més o menys anys de docència o el que presenta més activitat laboral. Davant l'obsessiva política educativa que equipara la formació permanent amb l'actualització $i$ ampliació dels seus nivells de coneixements acadèmics, no pocs mestres perceben el seu propi desenvolupament professional en termes de canvis a nivell de metodologia docent, de relació amb els alumnes o, senzillament, d'un relaxat equilibri entre la seva activitat laboral i els seus compromisos familiars o personals.

Tocant a aquest aspecte, cal destacar la important investigació realitzada per Huberman i els seus col-Jaboradors sobre una mostra de 160 mestres de secundària suïssos, en la qual es combinen metodologies quantitatives i qualitatives. A partir d'un model general de la carrera docent centrat en tres grans fases (fase I o d'iniciació, subdividida a la vegada en "començaments facils vs. difícils", fase II subdividida en "estabilització vs. posada en quüestiós i fase III 
o de resolució ("positiva», "negativa» i "experimentació-tenovació"), l'anàlisis temàtica dels protocols li permet d'establir una tipologia d'itineraris professionals en què intervenen tant factors històrico-contextuals (maig del 68, per exemple), com variables psicogenètiques, més concretament l'edat. D'altra banda, les seves dades recolzen, parcialment, en la hipòresi d'un gradual desengagement al llarg de la "carrera" docent. Segons les respostes a la tècnica del Diferencial Semàntic, els mestres amb més de 12 anys d'experiència (els quals, de mitjana, són per damunt dels 40 anys d'edat) tendeixen a minvar llur activitat i compromis encara que augmentin llurs nocions de serenitat, autoconfiança i eficiència. És com si existís un model compensatori de la dedicació, amb el creixement de l'activitat serena i el sentiment de la capacitat a càrrec d'una pèrdua de la implicació (Huberman, 1988; Huberman, 1989: 311 i ss.) ¿En quina mesura aquesta tendència general vers el replegament obeeix a una seqüència ontogenètica de desenvolupament, condicionada alhora pels canvis fisiològics causats per l'edat, o, al contrari, és la conseqüència dels sentiments de desilusió provocats per la frustació dels intents de canvi institucional de la dècada del 70? ¿Poden equiparar-se les condicions socials, economiques, polítiques... sota les quals van iniciar llur socialització professional els mestres que avui tenen entrc 40 i 50 anys, amb les circumstàncies dels que actualment accedeixen a la docència? ¿ $\mathrm{Hi}$ ha, al marge de les diferències internacionals, uns universals en la trajectòria ocupacional dels docents europeus? Més concretament, ¿̨ins a quin punt les dades $i$ els conceptes relatius a la socialització ocupacional deis mestres anglesos, suïssos, holandesos o dels USA són susceptibles d'aplicació en el context espanyol? ¿Quant n'hi ha, d'uinstitucional i i quan de "personal" a cada "carrera" docent?

Tot això ens remet al tema inicial, és a dir, al problema de la socialització adulta: ¿què canvia i què roman al llarg del cicle vital? ¿Com afecta la nostra identitat personal, la nostra autoimatge professional i a l'inrevés? ${ }_{2}$ Hi ha crisis que es poden predir? El nostre "excursus" sobre la "carrera" docent ens cvidencia, efectivament, que no solament els nens o cls joves estan sotmesos als avatars de l'aprenentatge social, sinó que també els adults canviem o preservem la nostra identitat personal $e n$ un constant intercanvi amb les institucions. Fins i tot un itinerari ocupacional tan poca cosa, per a alguns, com el d'un mestre d'escola se'ns revela, en mirar-lo més de prop, molt més complex i discontinu que el que afirmen els tòpics. L'edat cronològica, el gènere i les circumstàncies familiars, el context organitzatiu-institucional i la pròpia dinàmica sòcio-històrica s'entremesclen fornin unes trajectòries biogràfico-professionals que són, òbviament, idiosincràtiques. Altrament dit, a despit de les seves limitacions i de no poques contradiccions, aquestes investigacions, tant les que es reclamen sociològiques com les que cauen a l'àrea de la psicologia del cicle vital, ens ofereixen un enfocament de la socialització en el qual compten tant els processos 
"Papers": Revista de Sociologia

d'homogenització sòcio-cultural com els de diferenciació personal, el pes de les estructures socials, però també la importància de l'acció humana al llarg del cicle vital.

\section{BIBLIOGRAFIA}

Ackinson, P. y Delamont, S. (1985), "Socialisation into Teaching: the research wich lost ist way", British Journal of Sociology of Education, vol. 16 (3), pp. 307-322.

Bali, S.J. y Goodson, I.F. eds. (1985), Teachers, Lives and Careers, Londres, The Falmer Press.

Barber, B.A. y Miller, J. (1982), "Teacher Burn-out: A Psychoeducational Perspective", Eucational Digest, núm. 64, pp. 23-25.

Becker, H. (1952), "The career of Chicago public scholtcacher", reproduit a Hammersley, M. y P. Woods, eds. The Process of Schooling, Londres, Open University, 1976 , pp. $75-81$.

Becker, H. (1968), "El Yo y la socialización adulta", a Torregrosa, J.R. cdit. Teoría e investigación en la Psicologia Social actual, Madrid, I.O.P., 1974, pp. 645-659.

Burke, P.J. et allii (1983), "Teaching Life-Span Development. An Instrument to Identify Stages of Teacher Growth", Paper mecanografiat, Annual Meeting of AERA, Montreal, abril, 1983.

Cohen, G. ed. (1987), Social Change and the Life Course, Londres, Tavistock.

Cole M. and S.Walker (1990), Teaching and Streess, Buckingham, Open University Press.

Devereux, G. (1939), "Una teoría sociológica de la esquizofrenia”, a Devereux G. Ensayos de Etnopsiquiatria general, Barcelona, Barral, 1971, pp. 227-258.

Erikson, E.H. (1959), Identity and the Life Cycle: Select Papers, N. York. International Universities Press.

Esteva, C. (1973), "Cultura, sociedad y salud mental", cn Esteva, C. Cultura y personalidad, Barcelona, Redondo, pp. 88-149.

Estevc, J.M. (1984), Profésores en conflicto. Repercusiones de la práctica profesional sobre la personalidad de los enseñantes, Madrid, Narcea.

Freedman, S. (1986), "Teachers Butn Out vs Institutional Stress", Comunicación mecanografiada, Westhill International Sociology of Education Conference, Birmingham.

Fulicr, F.F. (1969), "Concerns of leachers: A developmental Conceptualization", American Educational Research Journal, núm. 6, pp. 207-226.

Giddens, A. (1980), La estructura de clases en las sociedades avanzadas, Madrid, Alianza Universidad.

Gould, R.L., "Transformations during Early and Middle Adult Years" en Smelser, N.J. y E.H. Erikson (1981), ob. cit, pp. 213-239. 
Habermas, J. (1986), Problemas de legitimación en el capitalismo tardio, Buenos Aires. Amorrortu.

Huberman, M. (1988), "Teacher Careers and School Improvment", Journal of Cu" riculum Studies, vol. 20, núm. 2, pp. 119-132.

Huberman, M. (1989), La vie des enseignants Nauchatel, Delachaux er Niersl.

Johson, M. (1983), "Professional Careers and Biographies", en Dingwall, R. y P. Lewis, (eds.) The Sociology of Profesions, Londres, Mc. Millan, pp. 242-262.

Lacey, C. (1977), The Socialisation of Teachers, Londres. Methuen.

Levinson, D.J. (1981), "Toward a Conceprionof of the Adult Life Course", en Smel. ser, N.J. y Erikson, E.H. (1981), ob. cit. pp. 265-290.

Lortie, D.C. (1977), School-Teacher: A Sociological Study, Chicago, Univ. of Chicago Press.

Mortimer, J.T. (1988), "Work Experinece and Psycological Cange Throught the Life Course" en W. Riley M. (ed.) Social Estructures \& Human Lives, N. York, Sage, pp. 267-284.

Nias, J. (1985), "A More Distant Drummer: Teacher Development as the Development of selfy, en Barton, L. y S. Walker, (eds.) Education and Social Change, Londres, Croom Helm, pp 3-28.

Prick, L.G.M. y B. van dex Hortst (1988), "Career Development Training for Teachers", paper mecanografiat, Xlil Conference of ATEE, Barcelona.

Reigharr, P.A. (1984), "Teacher Development from a Career Development Perspective", Paper mecanografiat, Annual Meeting of AERS, New Orleans.

Sikes, P. er allii (1985), Teacher Careers. Crises and Continuitties, Londres, Felmer Press.

Smelser, N.J. y E.H. Erikson, eds. (1981), Themes of Work and Love in Adulthood, Cambridge, Harward University Press. 